\title{
EVALUACIÓN DE LA COMPOSICIÓN NUTRICIONAL, ANTINUTRICIONAL Y BIODISPONIBILIDAD IN VITRO DE DIFERENTES EXTRACTOS FOLIARES
}

\author{
EVALUATION OF THE NUTRITIONAL AND \\ ANTINUTRITIONAL COMPOSITION AND IN VITRO \\ BIOAVAILABILITY OF FOLIAR EXTRACTS
}

\author{
Sayda Milena Pico F. (1,2), Dayron Gutiérrez (2), Ingrid Aragón G. (2), Andrés Escobar S. (2), \\ Darwin Ortiz (2), Teresa Sánchez (2), Paola Imbachí N. (2,3) Helena Pachón (2) \\ (1) Universidad Industria de Santander, Bucaramanga. Colombia \\ (2) Centro Internacional de Agricultura Tropical, Palmira. Colombia \\ (3) Universidad del Cauca, Popayán. Colombia
}

\begin{abstract}
Foliar extracts (FEs) are an alternative to address food and nutrition insecurity. FEs and leaves of cassava, bean, sweet potato and alfalfa were evaluated for nutrient and antinutrient composition and in vitro nutrient bioavailability. Bean FE had a high average $\pm(S D)$ iron concentration (1006 $\pm 8.49 \mathrm{mg} / \mathrm{kg})$, as did cassava FE for zinc $(110.1 \pm 6.72 \mathrm{mg} / \mathrm{kg})$ and soluble protein $(34.23 \pm 3.81 \mathrm{~g} / \mathrm{kg})$ concentration. For the cassava, bean and alfalfa FEs in vitro protein digestibility was greater than $71.18 \%$; in vitro iron dialyzability was less than 2.29\%; the phytate:zinc molar ratio was less than 0.08 , and the in vitro all-trans- $\beta$-carotene bioavailability was greater than $23.85 \%$. These values suggest a high protein, zinc and all-trans- $\beta$-carotene bioavailability and a low iron bioavailability. FEs can be a nutritious alternative for those countries with low dietary diversity.

Key words: foliar extract; leaf concentrate; in vitro bioavailability; nutrients; antinutrients.
\end{abstract}

Este trabajo fue recibido el 26 de Julio de 2010 y aceptado para ser publicado el 18 de Mayo de 2011.

\section{INTRODUCCIÓN}

Las deficiencias nutricionales son temas de salud prioritarios en países en vía de desarrollo, dado que pueden ocasionar un detrimento a la salud con importantes consecuencias individuales y sociales en una población (1). En búsqueda de una solución a esta situación en diferentes países se crearon organizaciones (2-4) que utilizan las hojas de las plantas para obtener un concentrado denominado extracto foliar (EF) (5) que puede apoyar simultáneamente las deficiencias más relevantes, entre ellas la de nutrientes como hierro, zinc y vitamina A(5). Informes de la Association pour la Promotion des Extraits Foliaires en nutrition (APEF) (3) muestran valores promedio, para el EF de alfalfa, de proteína $(539,38 \mathrm{~g} / \mathrm{kg})$, hierro $(563 \mathrm{mg} / \mathrm{kg})$, $\beta$-caroteno $(920 \mathrm{mg} / \mathrm{kg})$ y zinc $(17,92 \mathrm{mg} / \mathrm{kg})$, así como de otros nutrientes: fósforo, calcio, potasio y magnesio.

El EF puede mejorar diferentes parámetros del estado nutricional en humanos. Estudios demuestran que mejora el peso y la talla en niños de 6 a 12 años (6); componentes sanguíneos como ferritina sérica y hemoglobina en mujeres anémicas (7); proteína C reactiva en hombres (8) y absorción de algunos componentes como el $\beta$-caroteno y el acido fólico $(7,9)$.

El objetivo del presente estudio fue analizar la concentración de proteína soluble, hierro, all-trans- $\beta$ caroteno y zinc en los extractos foliares de varios cultivos, incluido el de alfalfa; evaluar la biodisponibilidad in vitro de proteína, hierro, all-trans- $\beta$-caroteno y zinc y cuantificar el contenido de algunos antinutrientes en todos los EFs y de $\mathrm{HCN}$ en las hojas y EF de yuca.

\section{MATERIALES Y MÉTODOS}

Muestra. Se seleccionaron los cultivos de yuca (Manihot esculenta crantz), batata (Ipomoea batatas) y 
fríjol (Phaseolus vulgaris). Se utilizó la variedad GUA 86 de yuca, cosechada a los 77 días, sembrada en suelos del Centro Internacional de Agricultura Tropical (CIAT), en el municipio de Palmira (Colombia), suministrada por el Consorcio Latinoamericano y del Caribe de Apoyo a la Investigación y al Desarrollo de la Yuca (CLAYUCA). Se utilizaron las variedades 440286 y 422656 de batata, cuya cosecha se hizo a los 40 y 80 días de la siembra, respectivamente, cultivadas en suelos de CIAT-Palmira y suministradas por CLAYUCA. Se utilizó la variedad CAL 96 de fríjol, cosechada a los 30 días en el municipio del Darién (Colombia) y suministrado por el Programa de Mejoramiento Genético de Fríjol - CIAT. De los tres cultivos se utilizaron las hojas para obtener los EF. Las hojas se cosecharon en etapa de prefloración, cuando las raíces y granos ya han obtenido la mayoría de nutrientes concentrados en la hoja (10), tomando la parte alta de la planta para minimizar la contaminación del suelo y se empacó en bolsas de plástico limpias, secas y libres de polvo. Con base en el color verde característico, se desecharon las hojas que presentaban daños mecánicos como golpes, cortaduras o cualquier tipo de laceración, al igual que las que mostraban ataques por insectos.

Obtención del EF. Las hojas cosechadas se sometieron a un proceso de limpieza. Se lavaron durante 10 segundos por aspersión con agua corriente y se introdujeron en recipientes plásticos para lavarlas por inmersión en agua $18 \mathrm{M} \Omega$ durante 2 minutos aproximadamente. Se escurrieron y se secaron con toallas de papel. Las hojas se sometieron al protocolo de separación de EFs (figura 1) que promueven APEF (método artesanal) (3) y la Asociación Soya de Nicaragua (SOYNICA) (método

\section{FIGURA 1}

Elaboración de extractos foliares por el método artesanal de APEF (6) y casero de SOYNICA (7)

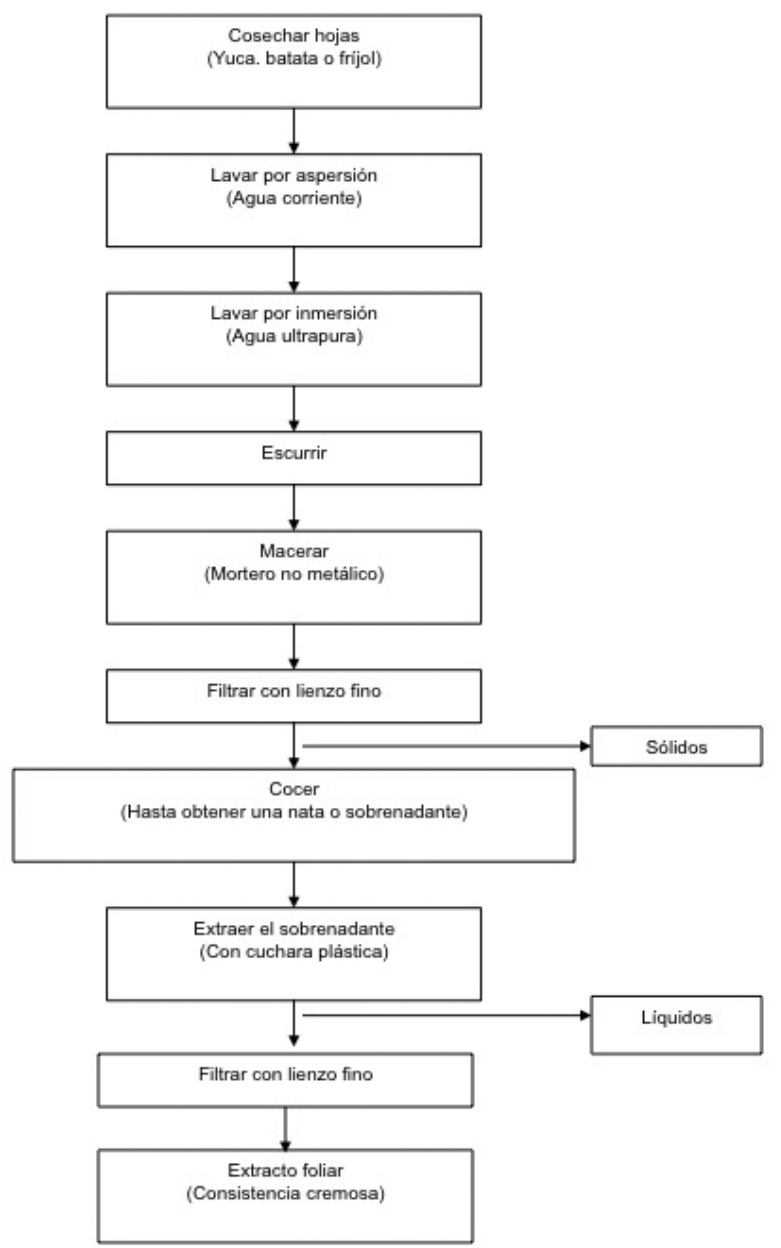


casero) (2). Una muestra de 2000 g EF de alfalfa en migas fue enviada desde Francia por APEF. Su llegada a CIAT-Palmira fue en octubre del 2007 y desde ese momento se conservó en un lugar seco y cubierto hasta su análisis en julio del 2008.

Liofilización de las muestras. Las muestras de hojas y EF (excepto el EF de alfalfa) se congelaron a una temperatura de $-80^{\circ} \mathrm{C}$ (Revco Thermo Scientific, Asheville, EEUU) y se liofilizaron (Labconco, Kansas, EEUU) por 2 días. Todas las muestras liofilizadas se sometieron a molienda (molino de bolas de circonio. elaborado artesanalmente) para su posterior análisis.

Composición nutricional. La concentración total de hierro y zinc se midió por espectroscopía de absorción atómica (EAA), usando el método de Benton-Jones et al. (11). El contenido proximal de nitrógeno se determinó por método colorimétrico (12). La determinación de la proteína soluble se realizó por el método de Lowry et al. (13). La cuantificación de all-trans- $\beta$-caroteno se realizó por cromatografía líquida de alta eficiencia (HPLC) (14). La medición de triptófano se realizó por el método colorimétrico de Nurit et al. (15).

Análisis de retención de compuestos en el EF. Se analizó el porcentaje de retención para determinar la variación de la concentración de cada nutriente en el proceso, usando la siguiente fórmula (16):

$$
\% \text { de Retención }=\frac{\text { valor } B}{\text { valor } A} \times \frac{\text { valor } D}{\text { valor } C} \times 100
$$

Valor $\mathrm{A}=$ (\% de materia seca de las hojas liofilizadas $)$ $\mathrm{X}$ (concentración de nutrientes en las hojas liofilizadas (base seca))

Valor $\mathrm{B}=(\%$ de materia seca del EF liofilizado) $\mathrm{X}$ (concentración de nutrientes en el EF liofilizado (base seca)) Valor $\mathrm{C}=$ gramos de hojas en base fresca

Valor $\mathrm{D}=$ gramos de $\mathrm{EF}$ en base fresca

Composición antinutricional. Las hojas de yuca contienen glucósidos cianogénicos que al hidrolizarse originan ácido cianhídrico $(\mathrm{HCN})$ y producen efectos tóxicos en el organismo (17). Por este motivo, a las hojas de yuca y su EF (pasta húmeda y liofilizada) se les determinó la cantidad de HCN (18). El contenido de fitatos totales de muestras liofilizadas de EFs se determinó en 3 fases: extracción siguiendo el método de Lehrfeld (19), purificación y cuantificación de fitatos según el método de Burbano et al. (20).

Biodisponibilidad in vitro. Se midió la biodisponibilidad in vitro de hierro, zinc, proteína y all-trans$\beta$-caroteno.

Determinación de hierro dializable mediante una metodología in vitro. La biodisponibilidad relativa de hierro en los EFs se estimó con el método planteado por
Miller et al. (21) y modificado por Argyri et al. (22). La cantidad de muestra utilizada fue de $1 \mathrm{~g}$.

Los resultados se expresaron como porcentaje de hierro dializado $(\mathrm{dlz})(21)$ :

$$
\% \mathrm{Fedl} z=\frac{[\mathrm{Fe}] \text { total en } \mathrm{dl} z(\mu \mathrm{g} / \mathrm{ml}) \times \text { volumen total } \mathrm{dl} z(\mathrm{~mL})}{\text { Fe total en muestra }(\mu \mathrm{g})} \times 100
$$

Determinación proximal de biodisponibilidad de zinc. La biodisponibilidad proximal de zinc se evaluó mediante la relación molar fitato:zinc. Según la Organización Mundial de la Salud (OMS), una relación fitato:zinc menor de 5:1 demuestra una alta biodisponibilidad de zinc, entre 5:1 y 15:1 una mediana biodisponibilidad y superior a 15:1 una baja biodisponibilidad (23).

$$
\text { Relación molar }=\frac{\frac{m g \text { fitatos } / 100 \mathrm{~g}}{660}}{\frac{\mathrm{mg} \text { zinc } / 100 \mathrm{~g}}{65.4}}
$$

Determinación de digestibilidad de proteína mediante una metodología in vitro. En el análisis se empleó el método de Hsu et al. (25), modificado por McDonough et al. (26). El porcentaje de digestibilidad se calculó uitlizando la siguiente fórmula, donde $\mathrm{X}$ representa el $\mathrm{pH}$ a los 10 minutos (25):

$$
\% \text { digestibilidad }=210.46-18.10 \mathrm{X}
$$

Determinación de bioaccesibilidad de all-trans $\beta$-caroteno mediante una metodología in vitro. Se simuló la digestión de acuerdo a Failla et al. (27).

Análisis estadístico. Para evaluar si la retención de nutrientes, antinutrientes y la biodisponibilidad in vitro de nutrientes era diferente entre los EFs, se corrió una prueba Kruskal-Wallis. Este método, no paramétrico, se aplicó porque los datos no cumplían los supuestos de un análisis de varianza (ANOVA). Un resultado se consideraba estadísticamente significativo si el p<0,05. Si la prueba arrojó resultados estadísticamente significativos, se realizó una prueba post-hoc de Bonferroni para explorar cuáles EFs tenían diferencias entre sí. Estos análisis se realizaron en la versión 9 del programa Stata (StataCorp, College Station, EEUU).

\section{RESULTADOS Y DISCUSIÓN RESULTADOS}

En la tabla 1 se presentan los resultados de la concentración de hierro, zinc, nitrógeno, proteína soluble, triptófano, all-trans- $\beta$-caroteno, HCN y porcentaje de materia seca para muestras liofilizadas del EF de alfalfa, las hojas de yuca, batata y fríjol con sus respectivos EFs. Análisis de las hojas y los EFs registraron contenidos 


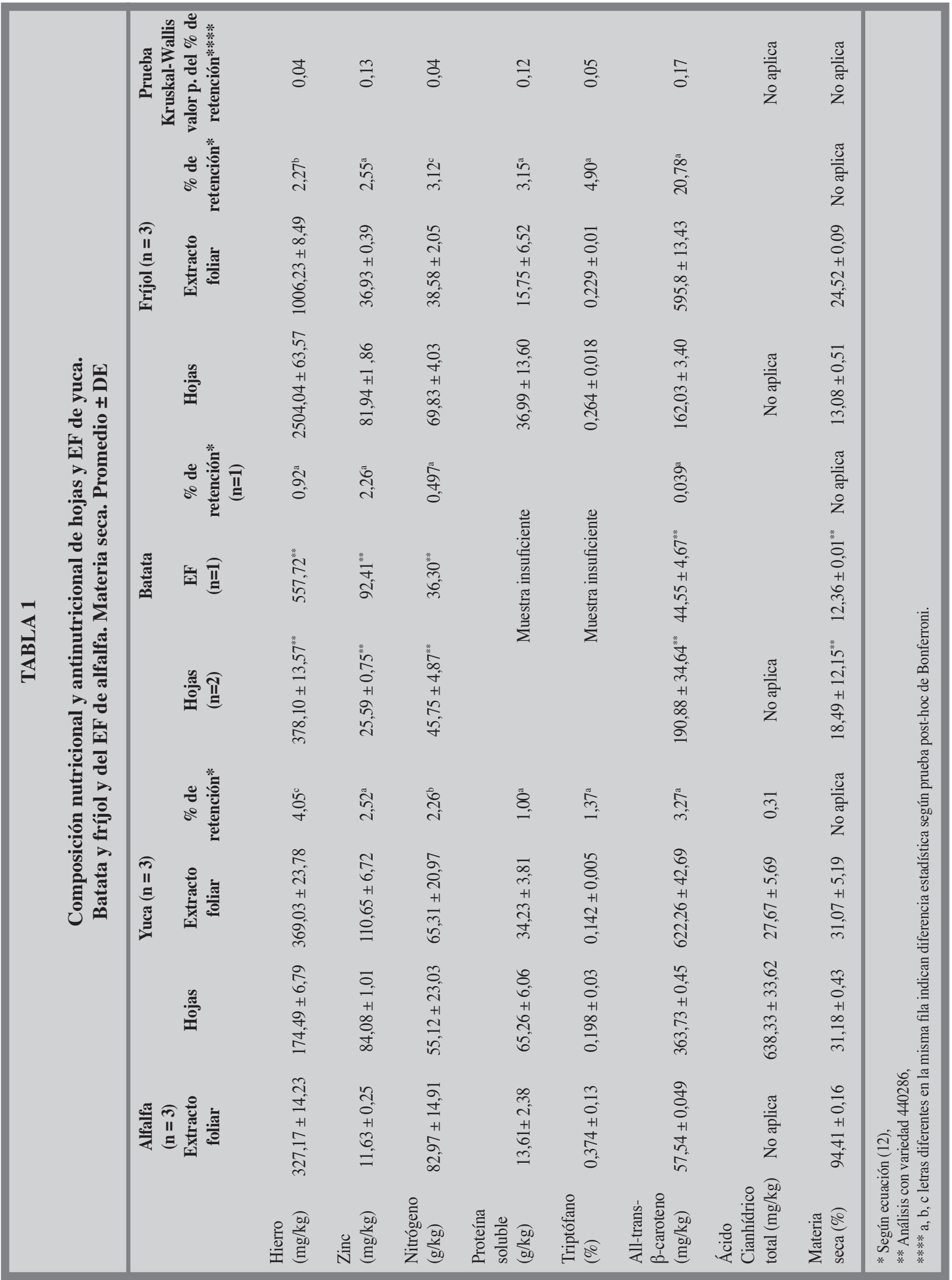


mayores a $174 \mathrm{mg} / \mathrm{kg}$ de hierro, $11 \mathrm{mg} / \mathrm{kg}$ de zinc, 36 $\mathrm{g} / \mathrm{kg}$ de nitrógeno, $13 \mathrm{~g} / \mathrm{kg}$ de proteína soluble, $0,142 \%$ de triptófano, $44,55 \mathrm{mg} / \mathrm{kg}$ de all-trans- $\beta$-caroteno y 27 $\mathrm{mg} / \mathrm{kg}$ de HCN total. Además, se analizó el contenido de $\mathrm{HCN}$ en la pasta húmeda indicando que la hoja de yuca contiene $4,33 \mathrm{mg} / \mathrm{kg} \pm 0,58 \mathrm{de} \mathrm{HCN}$ libre y $66 \mathrm{mg} / \mathrm{kg} \pm$ 1,73 de HCN total y su EF $17,67 \mathrm{mg} / \mathrm{kg} \pm 3,79$ de $\mathrm{HCN}$ libre (datos no publicados).

El porcentaje de retención de hierro y nitrógeno entre los EFs de yuca, batata y fríjol fue estadísticamente diferente $(\mathrm{p}<0,05)$ (tabla 1$)$. Para el resto de elementos estudiados, el porcentaje de retención no fue estadísticamente diferente $(\mathrm{p}>0,05)$, excepto para la retención de all-trans- $\beta$-caroteno en fríjol ( $21 \%$ ), todos mostraron una retención menor al $5 \%$. El EF de batata fue el que menor retención de todos los nutrientes tuvo en comparación con los demás. La retención de zinc fue la más alta en comparación con los demás nutrientes (2,26-2,55\%).

No hubo suficiente muestra para realizar el análisis de proteína soluble y triptófano para el EF de batata; por tener un rendimiento muy bajo, la materia prima fue insuficiente en comparación a las demás, por este mismo motivo se trabajaron 2 variedades distintas, la 440286 (resultados en la tabla 1) y la 422656 a la cual se le analizó la concentración de all-trans- $\beta$-caroteno en hojas $(341,7 \pm 20,35 \mathrm{mg} / \mathrm{kg})$ y en $\mathrm{EF}(25,54 \pm 4,53 \mathrm{mg} / \mathrm{kg})$.

La materia seca de las hojas y los EFs osciló entre 10 y $30 \%$ lo que indica el alto contenido de húmeda de las muestras.

En la tabla 2 se presentan los resultados de la biodisponibilidad in vitro de los EF. No hubo diferencia estadísticamente significativa para los tres EFs en la digestibilidad de proteína $(\mathrm{p}=0,06)$, se encontró diferencias estadísticas para el hierro dializable $(\mathrm{p}=0,01)$ en los EFs, sin embargo, el EF de alfalfa $(1,57 \pm 0,13 \%)$ y fríjol $(1,35 \pm 0,10 \%)$ fueron similares entre sí $(\mathrm{p}=0,08)$ y menores a yuca $(2,29 \pm 0,09 \%)(\mathrm{p}<0,05)$. La relación molar fitato:zinc del EF de alfalfa $(0,26 \pm 0,005)$ fue superior al EF de fríjol $(0,08 \pm 0,0008)$ y ésta a su vez fue mayor al EF de yuca $(0,02 \pm 0,0016)(\mathrm{p}<0,05)$. Finalmente, la bioaccesibilidad de all-trans- $\beta$-caroteno en los EFs no fue estadísticamente diferente para los EFs de yuca, batata y fríjol $(\mathrm{P}>0,05)$, pero sí estadísticamente diferente a la alfalfa $(\mathrm{p}<0,05)$.

El EF que mayor rendimiento presentó fue el de fríjol $(30,17 \%)$. seguido por el de yuca $(1,92 \%)$ y el de batata $(0,86-0,94 \%)$.

Los resultados obtenidos fueron comparados con estudios que reportan trabajos similares.

\section{BATATA}

HOJAS: Para el presente estudio, la composición de las hojas de batata, en materia seca, fue de $378,10 \mathrm{mg} /$ $\mathrm{kg}$ de hierro y $25,59 \mathrm{mg} / \mathrm{kg}$ de zinc. Estudios reportan contenidos de hierro en materia seca de $\sim 54-55 \mathrm{mg} / \mathrm{kg}$ y de zinc de 5,96-8,85 mg/kg (28). Bovell-Benjamin

\section{TABLA 2}

\section{Biodisponibilidad in vitro de proteína, hierro, all-trans- $\beta$-caroteno $y$ zinc de 4 extractos foliares, materia seca, promedio $+\mathrm{DE}$}

$\begin{array}{llll}\text { Alfalfa } & \text { Yuca } & \text { Batata } & \text { Fríjol }\end{array}$

\section{Prueba \\ Kruskal-Wallis, \\ valor $\mathbf{p}$}

$\%$ Digestibilidad

in vitro

de proteína

$\%$ Hierro dializable

in vitro

$$
78,05 \pm 5,39 \mathrm{a} \quad 71,18 \pm 1,87 \mathrm{a}
$$

$1,57 \pm 0,13 a$

$2,29 \pm 0,09 b$
Muestra

insuficiente

Muestra

insuficiente
$80,54 \pm 2,18 \mathrm{a}$

$0,06^{*}$

$1,35 \pm 0,10 \mathrm{a}$

$0,01 *$

$\%$ Bioaccesibilidad

in vitro de

all-trans- $\beta$-caroteno

$61,71 \pm 20,38 b$

$23,85 \pm 5,44 a$

$25,82 \pm 1,55 \mathrm{a}$

$32,33 \pm 13,61 \mathrm{a}$

$0,01 *$

Relación molar

fitato:zinc

$0,26 \pm 0,005 c$

$0,02 \pm 0,0016 \mathrm{a}$

Muestra

insuficiente

$0,08 \pm 0,0008 b$

$0,03 *$ 
reportó valores de hierro en materia seca de $\sim 26 \mathrm{mg} / \mathrm{kg}$ y el Centro Internacional de la Papa (CIP) obtuvo un promedio de $144 \mathrm{mg} / \mathrm{kg}$ para hierro en las hojas (materia seca). Sin embargo, al evaluar simultáneamente aluminio y encontrar un valor promedio superior $\sim 93,3 \mathrm{mg} / \mathrm{kg}$, el CIP concluyó que las hojas se habían contaminado con suelo (Gabriela Burgos. CIP, comunicación personal). En este estudio no se analizó aluminio y se limitó la contaminación del suelo en las hojas utilizando estrategias como cosecha de la parte superior de la planta, almacenaje en bolsas plásticas y lavado con agua 18 $\mathrm{M} \Omega$, entre otras, sin descartar que las hojas tuvieran contaminación.

La cantidad de nitrógeno en la hoja de batata $(45,75$ $\mathrm{g} / \mathrm{kg}$ ) está por encima de lo informado por BovellBenjamin $(\sim 5,98 \mathrm{~g} / \mathrm{kg})(28)$ e Ishida et al. $(\sim 3,74 \mathrm{~g} / \mathrm{kg})$ (29). La diferencia puede deberse a la edad de la planta en el momento de la cosecha de sus hojas. Sin embargo, las hojas de batata tienen mayor contenido de nitrógeno que sus tallos $(\sim 0,96 \mathrm{~g} / \mathrm{kg})$ y su tubérculo $(\sim 2,72 \mathrm{~g} / \mathrm{kg})$ (29). En general, reportes de Ishida et al. (28), indican que el contenido nutricional de la hojas de batata es mayor que el de su tubérculo, con la excepción del $\beta$-caroteno presente en el tubérculo de color anaranjado (peso fresco: 156,6 mg/kg) (28).

EF: La concentración de hierro, zinc, nitrógeno y all-trans- $\beta$-caroteno en el EF de batata fue de $557,72 \mathrm{mg} /$ $\mathrm{kg}, 92,41 \mathrm{mg} / \mathrm{kg}, 36,30 \mathrm{~g} / \mathrm{kg}$ y $44,55 \mathrm{mg} / \mathrm{kg}$, respectivamente. El EF de batata mostró una pérdida de nitrógeno y all-trans- $\beta$-caroteno, ocasionada quizás por la separación de sólidos y líquidos en el proceso filtración. El porcentaje de rendimiento en la producción del EF de batata fue menor del $0,90 \%$, lo que fue un limitante en el momento de preparar EF a partir de esta matriz.

Biodisponibilidad in vitro del EF: Se determinó la bioaccesibilidad in vitro de all-tran- $\beta$-caroteno en el EF de batata y se encontró que la eficiencia de la micelarización fue de $25,82 \%$. Al comparar el valor obtenido con el valor informado en un estudio de hojas de moringa (Moringa oleífera Lam) (25,2\% para $\beta$-caroteno), se encontraron tendencias similares, con la diferencia que éstas últimas se les adicionó aceite de maní como promotor de biodisponibilidad (30) y en el presente estudio fue adicionado yogurt como vehículo en la micelarización.

\section{YUCA}

HOJAS: La concentración nutricional de las hojas de yuca encontradas en el presente estudio son mayores a las reportadas por Chávez et al., para hierro (materia seca, 61,5-151 mg/kg) y zinc (materia seca, 39,2-63,7 $\mathrm{mg} / \mathrm{kg}$ ) (31), posiblemente por contaminación del suelo. Reportes de triptófano de Ngudi et al. (32) y Yeoh et al.
(33) oscilan entre $0,019-0,34 \%$; se obtuvo valores mayores en nuestro estudio, posiblemente relacionados con la variedad de la raíz y la edad de la planta (34). Estudios afines reportan datos de nitrógeno y all-trans- $\beta$-caroteno para las hojas de yuca similares a los del presente estudio, como el de Yeoh et al., que reportó entre 4,6 y 61,8 g/ $\mathrm{kg}$ de nitrógeno en materia seca (33) y el de Almeida et al., que reportó $370 \mathrm{mg} / \mathrm{kg}$ (34) para $\beta$-caroteno. El ácido cianhídrico $(\mathrm{HCN})$ está presente en los derivados de la yuca. Se encontró HCN total entre $216 \mathrm{mg} / \mathrm{kg}$ y $2600 \mathrm{mg} / \mathrm{kg}$ en hojas (materia seca) cuando se evaluaron en edad joven de 9 a 11 meses (datos inéditos, Teresa Sánchez). Los datos obtenidos para hojas frescas en el presente estudio $(638,33 \mathrm{mg} / \mathrm{kg})$ se pueden ubicar en estos intervalos.

EF: En el EF de yuca se encontró $20 \mathrm{mg} / \mathrm{kg}$ más zinc y $\sim 20 \mathrm{~g} / \mathrm{kg}$ menos nitrógeno que los informados por Modesti et al. (91,0 mg/kg zinc y 86,4 g/kg nitrógeno) (35), quien utilizó una metodología similar a la de este estudio para la obtención de un concentrado de hoja de yuca. La diferencia en la obtención del EF de yuca del presente estudio y la del concentrado de proteína de hoja de yuca, precipitado con calor en el estudio de Modesti et al (35), fue que en este último se adicionó metabisulfito de sodio antes del primer filtrado. Esto pudo ocasionar la precipitación de más nutrientes, y por consiguiente, las diferencias con los resultados del presente estudio. La retención de nutrientes en el EF de yuca fue menor o igual a 4,05\%. En el EF de yuca liofilizado el contenido de $\mathrm{HCN}$ fue $27,67 \mathrm{mg} / \mathrm{kg}$, lo que representa el $0,31 \%$ del contenido inicial de las hojas y un alto porcentaje de pérdida. Sin embargo, el Codex Alimentarius (37) indica una cantidad máxima de $10 \mathrm{mg} / \mathrm{kg}$ de $\mathrm{HCN}$ en harina de yuca, por lo que el EF de yuca no es apto para consumo humano.

Biodisponibilidad in vitro del EF: La biodisponibilidad in vitro del EF de yuca mostró que la digestibilidad de proteína en las hojas de yuca representa un $71,18 \%$ de la caseína utilizada como patrón de referencia. Modesti et al. (35) informa una digestibilidad proteica del $55,82 \%$ de un concentrado proteico similar al EF. La dializabilidad de hierro fue del 2,29\%, la más alta para los EFs del presente estudio; la relación molar fitato:zinc $<1$, lo que sugiere que el zinc es altamente biodisponible (23) y la bioaccesibilidad de all-trans- $\beta$ caroteno fue de $23,85 \%$ mostrando que el porcentaje de micelarización es alto.

\section{FRÍJOL}

HOJAS: Un estudio del contenido de hierro y zinc en hojas de fríjol de una misma variedad, cosechadas en el mismo suelo y aproximadamente a la misma edad de 
la planta de las del presente estudio, mostró cantidades de hierro $\sim 521,92 \mathrm{mg} / \mathrm{kg}$ y de zinc $\sim 30,44 \mathrm{mg} / \mathrm{kg}(10)$. Los valores informados en el presente estudio, para ambos nutrientes, son mayores debido a la ubicación de las hojas en el momento de la cosecha (10). Para los demás nutrientes no se encontraron estudios similares.

EF: Para el EF de fríjol no se encontraron informes publicados. En el EF de fríjol se puede exaltar el contenido de nitrógeno y triptófano debido a que fue el que presentó mayor concentración y retención.

Biodisponibilidad in vitro del EF: La biodisponibilidad in vitro del EF de fríjol mostró que la digestibilidad de proteína representa el 95,23\% de la caseína utilizada como patrón de referencia (dato no presentado), el hierro dializable fue del $1,35 \%$, que es baja; la relación molar fitato:zinc fue $<1$, lo que sugiere que el zinc es altamente biodisponible (23) y la bioaccesibilidad de all-trans- $\beta$-caroteno fue de $32,33 \%$ mostrando alta micelarización (30). Otro estudio mostró que la digestibilidad del grano de fríjol fue de $\sim 84,64 \%$ (36), muy cercana a la digestibilidad del EF $(80,54 \%)$ del presente estudio cuando se utiliza el mismo método de digestibilidad de proteína in vitro.

\section{EF DE ALFALFA}

COMPOSICIÓN: El EF de alfalfa enviado por APEF y analizado después de 13 meses en almacenamiento, mostró valores inferiores a los informados por Zanin (materia seca) (5) para hierro $\sim 700 \mathrm{mg} / \mathrm{kg}$ y zinc $20 \mathrm{mg} / \mathrm{kg}$, con un $\sim 50 \%$ de lo informado por APEF. El contenido de nitrógeno del EF de alfalfa mostró valores superiores a $88,01 \mathrm{~g} / \mathrm{kg}(5)$ y en el presente estudio el contenido de nitrógeno fue de $82,97 \mathrm{~g} / \mathrm{kg}$. La cantidad de $\beta$-caroteno fue de $92,0 \mathrm{mg} / \mathrm{kg}$ (5), pero sólo se evaluó su isómero all-trans- $\beta$-caroteno que fue de $57,54 \mathrm{mg} / \mathrm{kg}$. En resumen, los datos obtenidos en el presente estudio fueron inferiores a los encontrados en otra publicación (5).

Biodisponibilidad in vitro del EF de alfalfa: $\mathrm{La}$ digestibilidad de proteína del EF de alfalfa fue de 92,29\% respecto a la caseína patrón (dato no presentado). Este valor es alto, sugiriendo que un mayor porcentaje de la proteína de este EF puede ser asimilable por el organismo. Otro dato relevante en este EF es que la relación molar fitato:zinc es de 0,26, lo que muestra una alta biodisponibilidad de zinc (23).

\section{CONCLUSIONES}

Al procesar las hojas de yuca, batata y fríjol para producir EFs, hubo una baja $(<5 \%)$ retención de los nutrientes (tomando en cuenta las pérdidas de peso en la hoja fresca hasta obtener el EF liofilizado), con excepción de la retención de all-trans- $\beta$-caroteno en batata ( 21\%), lo que indica que el proceso de elaborar

EFs provoca grandes pérdidas en nutrientes. No obstante, las concentraciones de nutrientes en los EFs se mantienen elevadas con respecto a otros estudios. La biodisponibilidad in vitro de los EFs sugiere una alta asimilación de proteína, zinc y all-trans- $\beta$-caroteno y una baja asimilabilidad de hierro. El contenido de cianuro en el EF de yuca hace que no sea apto para el consumo humano. Por todo lo anterior, se puede concluir que el EF de fríjol fue el que mejor comportamiento mostró en rendimiento, propiedades nutricionales y biodisponibilidad in vitro de proteína y zinc; y sería la adición a las comidas de este EF el más indicado como una alternativa en programas de nutrición.

\section{RESUMEN}

Los extractos foliares (EF) son utilizados como complemento nutricional en países como Nicaragua y Tanzania. Se evaluaron hojas y EF de yuca, fríjol, batata y alfalfa, y se cuantificó los componentes nutricionales, antinutricionales y biodisponibilidad por métodos in vitro. En promedio (DE), el EF de fríjol tiene una elevada concentración de hierro $(1006,23(8,49) \mathrm{mg} / \mathrm{kg})$; el EF de yuca tiene alta concentración de zinc $(110,65(6,72) \mathrm{mg} /$ $\mathrm{kg})$ y proteína soluble $(34,23(3,81) \mathrm{g} / \mathrm{kg})$. Así mismo, la digestibilidad in vitro de proteína en los EFs de yuca, fríjol y alfalfa fueron superiores a 71,18\%; hierro dializable in vitro menor a 2,29\%; la relación molar fitato:zinc inferior a 0,08 y la bioaccesibilidad all-trans- $\beta$-caroteno superior a $23,85 \%$. Estos valores sugieren una alta asimilación de proteína, zinc y all-trans- $\beta$-caroteno, y una baja asimilabilidad de hierro. Los EFs pueden ser una alternativa nutricional en la alimentación en países que carecen de diversificación alimentaria.

Palabras clave: Extracto foliar; concentrado de hoja; biodisponibilidad in vitro; componentes nutricionales; componentes antinutricionales.

Dirigir la correspondencia a:

Profesora

Sayda Milena Pico Fonseca

CIAT

AA 6713

Cali, Colombia

Teléfono: (572) 4450000

$\mathrm{Eax} \cdot(572) 4450073$

saydamile@hotmail.com

Agradecimientos: A la Escuela de Nutrición y Dietética de la UIS por la formación académica de SMPF. A APEF por la donación del EF de alfalfa. A Álvaro Albán de CLAYUCA por el suministro de las hojas de batata 
y yuca, a Freddy Monserrate del Programa de Mejoramiento Genético de Fríjol - CIAT por el suministro de las hojas de fríjol y a José Restrepo de FIDAR por el suministro de las hojas de yuca. A Sonía Gallego y William Triviño de CLAYUCA, por facilitar el laboratorio de preparación de alimentos. A Servicios Analíticos del CIAT por los análisis de la concentración de hierro, zinc y nitrógeno. AAlejandra Lozano por la cuantificación de fitatos. A Marlene Rosero de AgroSalud por la edición del artículo. A la Universidad Ohio State por los análisis de bioaccesibilidad in vitro de all-trans- $\beta$-caroteno. $\mathrm{Al}$ Fondo Monsanto, por su aporte para la creación del Laboratorio de Calidad Nutricional del CIAT donde se realizaron los estudios de biodisponibilidad. Al Proyecto AgroSalud (CIDA 7034161) y el CIAT por el financiamiento del estudio.

\section{BIBLIOGRAFÍA}

1. Organización Panamericana de la Salud (OPS). Salud en las Américas. Washington D.C. (EEUU): OPS;2007.

2. Asociación Soya de Nicaragua (SOYNICA). Extractos foliares. Managua (Nicaragua): SOYNICA. [citado 2009 febrero 8]. Disponible en: http: //www. soynica.org.ni/\#.

3. Association pour la Promotion des Extraits Foliaires en nutrition (APEF). Les extraits foliaires de Luzerne. Paris (Francia): APEF. [citado 2009 febrero 8]. Disponible en: http: //www.nutritionluzerne.org/.

4. Protein for kids (PFK). Leaf Protein Concentrate. Medellin (Colombia): PFK. [citado 2010 mayo 24]. Disponible en: http://www.proteinforkids.com.

5. Zanin V. Un nuevo concepto nutricional para el ser humano: El EF de alfalfa. París (Francia): Association pour la Promotion des Extraits Foliaires en nutrition (APEF); 1998.

6. Doraiswamy T. Singh N. Daniel V. Effects of supplementing ragi (Eleusine coracana) diets with lysine or leaf protein on the growth and nitrogen metabolism of children. Br J Nutr 1969;23:737-43.

7. Vyas S. Collin S. Bertin E. Davys G. Mathur B. Leaf concentrate as an alternative to iron and folic acid supplements for anaemic adolescent girls: a randomized controlled trial in India. Public Health Nutr 2010;13:418-23.

8. Adrianasolo F. Leaf concentrate. Undernutrition. Nourishing inmates in Malagasy prisons. Public Health Nutr 2010;12: 440-1.

9. Devadas RP. Murphy NK. Biological utilization of beta-carotene from amaranth and leaf protein in preschool children. Rev Nutr Diet 1978;31:159-61.
10. Gamboa HA. Evaluación de la acumulación de hierro y zinc en cinco genotipos de fríjol común (Phaseolus vulgaris). [Tesis]. Cali (Colombia): Universidad del Valle; 2007.

11. Benton-Jones J. Wolf B. Mills H. Plan analysis handbook: A practical sampling. preparation. analysis and interpretation guide. Nueva York (EEUU): Micro-Macro publishing; 1991.

12. Skalar Analytical BV. The SANplus Segmented Flow Analyzer: Soil and plant analysis. Breda (The Netherlands): Skalar Analytical BV; 1995.

13. Lowry OH. Farr AL. Randall RJ. Protein measurement with the folin phenol reagent. J Biol Chem 1951;193:265-75.

14. Ferruzzi MG. Nguyen ML. Sander LC. Rock CL. Schwartz SJ. Analysis of lycopene geometrical isomers in biological microsamples by liquid chromatography with coulometric array detection. J Chromatogr 2001;760:289-99.

15. Nurit E. Tiessen A. Pixley K. Palacios N. Reliable and inexpensive colorimetric method for determining protein-bound tryptophan in maize kernels. $\mathbf{J}$ Agric Food Chem 2009;57:7233-8.

16. Rodríguez D. A guide to carotenoid analysis in foods. Washington D.C (EEUU): HarvestPlus; 2001.

17. Ceballos. H.. Ospina. B. La yuca en el tercer milenio: Sistemas modernos de producción. procesamiento. utilización y comercialización. Beneficios y subproductos. Cali. Colombia; 2002.

18. Sánchez T. Salcedo E. Ceballos H. Dufour D. Mafla G. Morante N. et al. Screening of starch quality traits in cassava (Manihot esculenta crantz). Starch 2009;61:12-9.

19. Lehrfeld J. HPLC separation and quantitation of phytic acid and some inositol phosphates in food: Problems and solutions. J Agric Food Chem 1994;42:2726-31.

20. Burbano C. Muzquiz M. Osagie A. Ayet G. Cuadrado C. Determination of phytate and lower inositol phosphates in Spanish legumes by HPLC methodology. Food Chem 1995;52:321-5.

21. Miller D. et al. An in vitro method for estimation of iron availability from meals. Am J Clin Nutr 1981; 34: 2248-56.

22. Argyri K. Birba A. Miller DD. Komaitis M. Kapsokefalou M. Predicting relative concentrations of bioavailable iron in foods using in vitro digestion: New developments. Food Chem 2009;113:602-7.

23. World Health Organization. Food and Agriculture Organization. International Atomic Energy Association (WHO. FAO. IAEA). Trace elements in human 
health and nutrition. Ginebra (Suiza): WHO; 1996.

24. International Zinc Nutrition Consultative Group (IZiNCG). Assessment of the risk of zinc deficiency in populations and options for its control. Food Nutr Bull 2004;25:S94-203.

25. Hsu HW. Vavak DL. Satterlee LD. Miller GA. A multienzyme technique for estimating protein digestibility. J Food Sci 1977;42:1269-73.

26. McDonough FE. Sarwar G. Steinke FH. Slump P. Garcia S. Boisen S. In vitro assay for protein digestibility: Interlaboratory study. J Assoc Off Anal Chem. 1990;73:622-5.

27. Failla M. Huo T. Thakkar M. In vitro screening of relative bioaccessibility of carotenoids from foods. Asia Pac J Clin Nutr 2008;17:200-3.

28. Bovell-Benjamin A. Sweet potato: A review of its past. present and future role in human nutrition. Adv Food Nutr Res 2007;52:1-59.

29. Ishida H. Suzuno H. Sugiyama N. Innami S. Tadokoro T. Maekawa A. Nutritive evaluation on chemical components of leaves. stalks and stems of sweet potatoes (Ipomoea batatas poir). Food Chem 2000;68:359-67.

30. Pullakhandam R. Failla M. Micellaritazion and intestinal cell up take of $\beta$-carotene and lutein from drumstick (Moringa oleifera) leaves. J Med Food 2007;10:252-7.
31. Chávez A. Sánchez T. Jaramillo G. Bedoya J. Echeverry J. Bolaños E. Ceballos H. et al. Variation of quality traits in cassava roots evaluated in landraces and improved clones. Euphytica 2005;143:125-33.

32. Ngudi D. Kuo Y. Lambein F. Cassava cyanogens and free amino acids in raw and cooked leaves. Food Chem Toxicol 2003;41:1193-7.

33. Yeoh H. Chew M. Protein content and amino acid composition of cassava leaf. Phytochem 1976;15:1597-9.

34. Almeida E. Fenandes S. Martins R. Talá E. $\beta$-carotene from cassava (Manihot esculenta Crantz) leaves improves vitamin A status in rats. Comp Biochem Physiol 2007;146:235-40.

35. Modesti C. Correa A. Oliveira E. Abreu C. Santos C. Caracterização de concentrado protéico de folhas de mandioca obtido por precipitação com calor e ácido. Cienc Tecnol Aliment 2007;27:464-9.

36. Cruz G. Oliveira M. Costa N. Pires C. Cruz R. Moreira M. Comparação entre a digestibilidade protéica in vitro e in vivo de diferentes cultivares de feijão (Phaseolus vulgaris 1.) armazenados por 30 días. Alim Nutr 2005;16:265-71.

37. World Health Organization. Food and Agriculture Organization (FAO/WHO). Food Standards Programme. Codex Alimentarius Commission XII. Supplement 4. Roma (Italia): FAO; 1991. 